\title{
INTELECTUALISMO EM MAX WEBER: O PROCESSO DE INTELECTUALIZAÇÃO COMO UM CAMINHO PARA COMPREENSÃO DO DESENVOLVIMENTO HISTÓRICO DO CONHECIMENTO
}

\author{
INTELLECTUALISM IN WEBER'S WORK: THE PROCESS OF INTELLECTUALIZATION \\ AS AN AVENUE FOR UNDERSTANDING KNOWLEDGE'S HISTORICAL \\ DEVELOPMENT
}

\author{
Veridiana Domingos CORDEIRO \\ Universidade de São Paulo (USP), São Paulo, Brasil. \\ veridiana.cordeiro@usp.br \\ https://orcid.org/0000-0001-9666-4386 (D) \\ Hugo NERI \\ Universidade de São Paulo (USP), São Paulo, Brasil. \\ hugo.munhoz@usp.br \\ https://orcid.org/0000-0001-6065-4661
}

A lista completa com informações dos autores está no final do artigo

\begin{abstract}
RESUMO
O objetivo deste artigo é discutir o conceito de intelectualismo (e outras noções derivadas) no corpus textual de Max Weber relativo aos escritos de religião a fim de pavimentar um caminho para bases de uma teoria sociológica do conhecimento, partindo da hipótese de que o processo de intelectualização seria o único fenômeno que envolveria, como um todo, os problemas epistemológicos e suas possíveis soluções. Para fins analíticos, intelectualismo é um complexo sistemático de elementos que formam um conjunto, e por isso o artigo se dedica à definição dos mesmos. Pelo exame do intelectualismo, chegamos a três caminhos diferentes que endereçam parte do complexo de problemas relativos ao conhecimento: a.) os problemas epistemológicos (de uma Erkenntnistheorie) mais centrais surgem quando tentamos definir o que é a magia, qual a sua relação com o mundo e qual a sua relação com o intelectualismo; b.) a forma da existência real do conhecimento e sua mudança estão na relação entre objetivação - interpretação e; c.) o conteúdo atual do conhecimento, sua mudança e a relação pragmática que este tem com as pessoas dependem do contexto semântico. PALAVRAS-CHAVE: Sociologia do Conhecimento, Max Weber, Sociologia da Religião, Intelectualismo,

Processo de Intelectualização
\end{abstract}

\begin{abstract}
In this article, we discuss the concept of "intellectualism" (and other stemmed notions) in Max Weber's religious textual corpus to pave a sociological theory of knowledge, since we hypothesize that the intellectualization process is the only phenomenon that involve epistemological problems and its possible solutions. For analytical purposes, intelectualism is a systematic complex of elements which should be defined. By examining the concept intellectualism, we conclude that there are three different pathways for addressing the complex of problems related to knowledge: a.) the most central epistemological problem (Erkenntnistheorie) emerges when we try to define what is magic; its relationship with the world; and its relationship with intellectualism; b.) the form of the real existence of knowledge and its changes are placed in the relationship between objectification and interpretation; c.) the current content of knowledge, its changes and the pragmatic relationship with semantic-context dependent people.
\end{abstract}

KEYWORDS: Sociology of Knowledge, Max Weber, Sociology of Religion, Social Theory, Process of Intellectualization. 


\section{1 - INTRODUÇÃO}

O objetivo deste artigo é discutir o conceito de intelectualismo (e outras noções derivadas) no corpus textual de Max Weber relativo ao tema da religião a fim de pavimentar um caminho para as bases de uma teoria sociológica do conhecimento. Para tal, partimos da hipótese de que o processo de intelectualização seria o único fenômeno que envolveria, como um todo, os problemas epistemológicos e suas possíveis soluções na obra de Weber. Para fins analíticos, sua forma conceitual pode ser bem representada como um complexo sistemático de elementos que formam um conjunto, exigindo, com isso, uma explicação total para este. Por isso, é necessário definir seus principais elementos. Quase todas as reflexões de Weber sobre o tema estão contidas em seus textos sobre religião (embora não se restrinja a eles, pois há outros escritos políticos e epistemológicos a respeito). Neles, os conceitos intelectual, intelectualidade e intelectualismo aparecem com frequência, ainda que não sejam auto evidentes.

Nesse sentido, ao longo do artigo, buscaremos responder à questão "o que é o intelectualismo?" para delinearmos as fronteiras do complexo de problemas expressado pelo processo de intelectualização. Para tal, nos basearemos em alguns textos escritos entre 1913 e 1920: Comunidades Religiosas (1913), Sobre algumas categorias da Sociologia Compreensiva (1913), Consideração Intermediária (1915), a Introdução (1913), O sentido da 'neutralidade valorativa' das ciências sociais e econômicas (1917), Confucionismo e Taoísmo (1919), Hinduísmo e Budismo (1920) e o inacabado Antigo Judaísmo (1920).

O termo intelectualismo é muito anterior à obra weberiana, mas nela aparece com certa centralidade no que diz respeito ao estudo das religiões. Fazendo um breve apanhado da trajetória do termo intelectualismo, o Historisches Wörterbuch der Philosophie v.4 argumenta que, assim como muitos termos que terminam em "ismo", "intelectualismo" foi cunhado com "significado pejorativo" (VERLAG, 1976, p. 439). A primeiríssima aparição do termo, aparentemente, está na obra de Francis Bacon, também em sentido pejorativo. A partir da segunda metade do século XIX, o termo intelectualismo "representou o antônimo de um novo conceito, o voluntarismo" (VERLAG, 1976, p. 440). Desta maneira, foi "apenas nesta contraposição [com o voluntarismo] que seu uso passou a ser gradualmente dissolvido dos termos 'idealismo' e 'racionalismo', ganhando de seu novo uso, na discussão psicológica de seu tempo, mais independência e contornos mais nítidos" (VERLAG, 1976, 
p. 440). O Historisches Wörterbuch der Philosophie v. 4 (VERLAG, 1976) ainda argumenta que Tönnies esclareceu, em um artigo de 1883, que "a intenção desta nova conceituação" demanda uma "mudança da atitude geral do espírito do intelectualismo para o voluntarismo" (VERLAG, 1976, p. 441). Interessante notar que, com isto, Weber certamente conhecia o sentido corrente da palavra e a empregou em um sentido não muito distante deste. Como visto, o intelectualismo pertencia ao âmbito das discussões psicologistas (como aparecia, por exemplo, em Wundt), porém, como Weber se posicionava contrariamente ao psicologismo, sua ênfase ora existencial, ora lógica, sobre o conceito acabam por torná-lo muito mais próximo de um sentido "cognitivista semântico" - sentido que assumimos aqui (NERI, 2014).

A ideia de definir o termo intelectualismo e seus correlatos na obra weberiana caminha em direção a uma explicitação do conhecimento e seu desenvolvimento histórico a partir das teorias weberianas. Weber, ao tratar do progresso teórico científico, emprega a expressão processo de intelectualização. Pelo exame do intelectualismo, chegamos, portanto, a três caminhos diferentes que endereçam parte do complexo de problemas relativos ao conhecimento: a.) os problemas epistemológicos (de uma Erkenntnistheorie) mais centrais surgem quando tentamos definir o que é a magia, qual a sua relação com o mundo e qual a sua relação com o intelectualismo; b.) a forma da existência real do conhecimento e sua mudança estão na relação entre objetivação - interpretação e; c.) o conteúdo atual do conhecimento, sua mudança e a relação pragmática que este tem com as pessoas dependem do contexto semântico. Faremos uma reconstrução conceitual até apontar esses três caminhos na conclusão.

\section{2- CONSIDERAÇÕES PRÉVIAS SOBRE INTELECTUALISMO NA OBRA WEBERIANA}

Para entendermos o que é intelectualismo, antes, é necessário mapear os diferentes momentos em que o conceito foi utilizado, os elementos que constituiriam e os que estariam apenas vinculados ao conceito de intelectualismo. A primeira ocorrência de maior expressividade do conceito está no sétimo parágrafo de Comunidades Religiosas, do texto "Estamentos, Classes e Religiões" [Stände, Klassen und Religionen]. Como veremos no excerto a seguir, Weber esboça um esquema de dois conjuntos de elementos, em que um deles é condicionado pelo outro:

Em medida extraordinariamente ampla, o destino das religiões esteve condicionado pelos diferentes rumos que o intelectualismo tomou, neste caso, 
e pela diversidade de relações deste [o intelectualismo] com o sacerdócio e com os poderes políticos; e, em contrapartida, essas circunstâncias foram condicionadas pela proveniência daquela camada que, em grau específico, era portadora do intelectualismo (WEBER, 2001, p. 266; WEBER, 2009, p. 340).

A exposição acima sugere um esquema de elementos sintéticos que expressa o contexto (ou parte do contexto) que o intelectualismo se manifesta e produz seus efeitos. Propomos que há dois momentos diferentes na assertiva de Weber, que representam, cada um deles, um conjunto de elementos e relações. O primeiro conjunto estaria condicionado pelo segundo. No interior do primeiro conjunto, os elementos estariam também dispostos em relações de condicionamento. Assim, teríamos: o destino das religiões condicionado pelo intelectualismo; o intelectualismo condicionado pelo sacerdócio e pelos poderes políticos. E, novamente, todo o primeiro conjunto seria condicionado pela proveniência da camada portadora do intelectualismo. Considerando que este esquema está localizado no sétimo parágrafo "Estamentos, Classes e Religiões", o fenômeno central da relação causal é a estratificação social. Portanto, assumimos que a proveniência da camada portadora do intelectualismo seja a posição na estratificação de certa sociedade a que essa camada pertence. Vale mencionar que o critério de mensuração da estratificação social de maneira universal é desenhado por Weber ao usar dois tipos-ideais bastante abstratos: a) as camadas sociais negativamente privilegiadas e b) as camadas sociais privilegiadas. O intelectualismo seria, assim, condicionado pelo gradiente da estratificação social que vai do menos privilegiado ao mais privilegiado. Daqui, levantamos duas questões: Qual é o grau de condicionamento que o intelectualismo sofre pela estratificação social? E, o que define uma camada social ser portadora do intelectualismo?

De volta ao primeiro conjunto, o condicionamento que o intelectualismo exerce sobre o destino das religiões está condicionado, por sua vez, pelo sacerdócio e pelos poderes políticos. Mas de que natureza poderia ser esta última relação de condicionamento? A relação dos poderes políticos com o intelectualismo só pode ser: a) negativa (ao intelectualismo não são permitidas certas "ações"); e/ou b) instrumentalista, (isto é, o intelectualismo é empregado para certas finalidades; em sentido pragmático). A relação do sacerdócio com o intelectualismo, ao contrário, é positiva (o intelectualismo produz "ideias" objetivas por meio dele). Podemos também relacionar, em grande parte, o destino das religiões ao desenvolvimento histórico (das concepções religiosas) que diferentes religiões engendraram.

Em resumo, o segundo conjunto diz respeito a camadas portadoras do intelectualismo sem adjetivação, isto é, sem um âmbito de ação efetiva. O primeiro 
conjunto, por sua vez, traça alguns contornos, destacando um contexto de desenvolvimento da religião/concepções religiosas com seus elementos centrais. Nesta relação, entre conjuntos de condicionamentos, o produto efetivo da ação do intelectualismo se manifesta no destino das religiões, relacionado, assim, ao desenvolvimento histórico do conhecimento.

Assim, para entender traços característicos do intelectualismo é preciso entender o que são e o que define as camadas portadoras do intelectualismo. Weber faz uma exposição sobre suas diferentes camadas portadoras, apontando elementos comuns que estariam presentes em todas elas - ainda que elas possuam condicionamentos distintos, por conta de suas diferentes proveniências sociais, e por estarem inseridas também em configurações sociais diferentes. Para tal, Weber opta por utilizar o termo camada [Schichte], que não se confunde nem com classe [Klasse], nem com estamento [Stand].

A primeira camada portadora do intelectualismo teria sido o sacerdócio. Ele é uma camada orientada para as condutas e práticas consideradas religiosas. Seu evento originador foi sua transformação em uma "agremiação de literatos [Literatenzunft]" (WEBER, 2001, p. 266; WEBER, 2009, p. 340). O termo de origem latina "literato" (literatus/litteratus) é utilizado para designar alguém com "estudo", isto é, alguém que passou por um processo de aprendizagem; a raiz da palavra equivale à "letra" (litera/littera), que sugere forte relação com a escrita. Com isso, o sacerdócio é uma camada que estabeleceu, em algum momento do tempo, um vínculo forte com a educação e, provavelmente, com a linguagem escrita. Os vínculos com a educação e a linguagem escrita sugerem que na (trans)formação do sacerdócio, pois este fixaria algo da tradição (religiosa/cultural) oral na linguagem escrita. Tal fixação cria uma nova condição e exigência de acesso à tradição em forma de escritura, a saber: o aprendizado da técnica da escrita, seja para a mera compreensão, para a interpretação, ou mesmo para uma objetivação (escrita) nova de uma interpretação. Assim, o ensino baseado na tradição escrita instruirá a habilidade de manuseamento e o domínio das formas da linguagem escrita.

Sobre a relação entre linguagem escrita e sacerdócio, é inviável a interpretação de que a causa necessária para fixação da tradição seja o sacerdócio, em geral, na escrita, dado que a escrita não tem sua existência determinada pela religião, nem mesmo sua origem deve ser vinculada a ela, como a expressão de uma necessidade- muito embora, encontremos na história casos de vínculos muito estreitos entre a escrita e a religião.

O sacerdócio, enquanto camada portadora do intelectualismo, desenvolve o "pensamento metafísico e ético". Mas, como Weber deixa claro, não há relações de 
exclusividade entre o desenvolvimento do pensamento ético e metafísico e o sacerdócio. Isso pois: apenas algumas camadas sacerdotais "souberam monopolizar, em grau muito forte, o desenvolvimento da metafísica e da ética religiosa" (WEBER, 2001, p. 266; WEBER, 2009, p. 340), como seria o caso, por exemplo, do zoroastrismo, do sacerdócio egípcio, do cristianismo antigo e medieval, do bramanismo do período védico, do judaísmo e do islã. $\mathrm{O}$ mesmo não ocorreria em uma série de outras religiosidades. No extremo Oriente, por exemplo, houve o clássico caso do confucionismo, que foi uma ética religiosa de burocratas (mandarins após a unificação imperial) não sacerdotes; já no Ocidente foram apontados casos dos povos da Antiguidade mediterrânea, habitantes de cidades, como os fenícios, os helenos e os romanos. Embora não fossem religiões universais, o maniqueísmo e o gnosticismo "eram religiões de intelectuais muito específicas, no que se refere a seus criadores, assim como eram também, essencialmente, seus portadores e o caráter de sua doutrina de salvação" (WEBER, 2001, p. 268).

Mas o que é essa tradição (tradição religiosa - cultural) que o sacerdócio fixaria na escrita? Para responder à questão sobre a definição de tradição religiosa e, com isso, a definição do que é religioso, retomaremos as proposições de Weber feitas no primeiro parágrafo de Comunidades Religiosas, "O surgimento da religião".

Comecemos pela definição prévia do termo "religioso". Após discorrer sobre o processo de formação de entidades mágico-religiosas, Weber formula a seguinte proposição: "Registramos como resultado deste processo o surgimento, por um lado, da 'alma', e por outro, dos 'deuses' e 'demônios', isto é, de poderes 'sobrenaturais' [übersinnlicher]. O ordenamento de suas relações em relação aos homens constitui o domínio da ação religiosa" (WEBER, 2001, pp. 126-7; WEBER, 2009, p. 281).

A ação 'religiosa' constrói o domínio religioso ao fazer de sua tarefa a construção de um conjunto de relações ordenadas entre o suprassensível e os homens. O efeito da ação religiosa em seu engajamento com a concepção das relações de um mundo suprassensível com o mundo dos homens é o domínio religioso. Desta maneira, a ação religiosa traz consigo dois problemas diretos: a) o que é o suprassensível (problema metafísico e ontológico); e b) quais são as relações (adequadas) entre o suprassensível e os homens (problema ético). A eles se somariam outros problemas indiretos, porém não menos importantes: a) o que é o homem? (problema antropológico); b) o que é este mundo? (problema ontológico) e, por fim, c) como saber se essas relações são adequadas? (problema de validade/verdade). Como já se pode notar aqui, e retomado posteriormente, a construção conceptual do suprassensível funciona como uma medida ordenadora de um 
mundo irracional, isto é, de um mundo que não possui sentido [Sinn] em si mesmo. Na continuação do argumento, a formulação do suprassensível enquanto ordenador do mundo irracional é intensificada, indicando sua relação com o conhecimento:

Não é a pessoalidade ou a impessoalidade, nem a impessoalidade dos poderes 'suprassensíveis' que é o primeiramente específico em todo esse desenvolvimento [da formação de entidades suprassensíveis]. Mas, agora, as coisas e acontecimentos, que existem e acontecem, não apenas desempenham um papel na vida, mas vão para além disso, já que e porque eles 'significam' [bedeuten] algo [isso é o específico]" (WEBER, 2001, p. 127; WEBER, 2009, p. 282).

O termo "suprassensível" traduz o adjetivo alemão "übersinnlich" de maneira literal. Embora contenham os mesmos radicais (supra = über; sensum = sinn), o termo "sentido" em língua portuguesa, quando adjetivado, aponta imediatamente para a acepção de sensibilidade. A manutenção do radical da palavra alemã sem alterações morfológicas auxilia na compreensão mais eficaz da concepção de um sentido transcendente. Como efeito da concepção de sentido transcendental (isto é, da concepção metafísica do suprassensível) as coisas e os acontecimentos do mundo passam a significar algo. Ou seja, por meio deste sentido transcendente (do suprassensível) o mundo passa a ser significativo. É importante definir o que Weber entende por significado e, também, por sentido, sabendo que o significado engendra os signos ou símbolos, impulsionando a (con)formação de um mundo simbólico.

Após todos os argumentos feitos acima, entendemos por tradição religiosa a sedimentação de um conjunto de soluções dadas ao problema da relação do suprassensível [übersinnlich] com o mundo dos homens. Ademais, este conjunto de soluções também faz parte do pensamento metafísico e ético.

Além do sacerdócio, o segundo exemplo de camadas portadoras do intelectualismo, que Weber menciona, é a camada monacal. Assim como o sacerdócio, seu interesse principal esteve no domínio da religião, envolvendo-o com questões éticas e metafísicas. Em sentido prático, a camada monacal atua paralelamente ao sacerdócio ou, por vezes, em seu lugar. Historicamente, o monacato esteve presente em todos os ramos do budismo, no cristianismo antigo e medieval, e também no islamismo. Sua atuação em relação ao conhecimento foi muito mais ampla que a atuação do sacerdócio, sobretudo o monacato cristão da Idade Média. Isto é, seu interesse sobre uma investigação do mundo empírico foi mais amplo. Envolveram-se com empreendimentos científicos que tinham, eventualmente, proximidade com as ações mágicas. Composições literárias de vários tipos 
foram objeto de seu interesse e produto de suas ações, com destaque para sua produção teológica.

Uma terceira camada portadora do intelectualismo é composta por cantores e poetas, que nomearemos aqui de camada artística. Por não estar necessariamente relacionada à religião, ela é um caso limítrofe. Na relação entre a proveniência das camadas portadoras do intelectualismo e o destino das religiões, a camada artística é explorada em menor grau por Weber. Ela seria mais bem explorada em outros textos, como o estudo sobre a música. Quando há, porém, a relação desta camada com a religião, ela pode ser notada, por exemplo, no conjunto de textos que formam a escrita sagrada: o cânone. Bons exemplos são os Vedas e, em parte, a Tanakh. Quando a educação não foi monopolizada pelas camadas religiosas, a influência da camada artística sobre o pensamento metafísico e ético possui mais importância. O melhor exemplo é o da Grécia pré-filosófica (e até mesmo filosófica) com os poetas clássicos fundadores, ou melhor, sistematizadores da tradição: Homero, Hesíodo e, posteriormente, os autores trágicos, como Ésquilo.

Nos casos em que o pensamento metafísico e ético não é elaborado apenas por camadas sacerdotais ou estritamente dependentes da religião, vemos que este pensamento pode ser elaborado por outros domínios e com outras finalidades, que não as do domínio religioso. A principal ilustração para este argumento está na formação e desenvolvimento da filosofia clássica grega:

\begin{abstract}
Dentro de determinada situação religiosa, as camadas intelectuais podem então constituir um empreendimento com caráter de escola, semelhante, por exemplo, à academia platônica e as escolas helênicas de filosofia afins, e, neste caso, assim como aquelas, não tomam oficialmente posição alguma em relação à prática religiosa existente, também não se afastam diretamente dela, mas dão-lhes uma nova reinterpretação filosófica [philosophischen umdeuten] (WEBER, 2001, pp. 268-9; WEBER, 2009, p. 342).
\end{abstract}

Ou seja, as escolas filosóficas também são portadoras do intelectualismo, ainda que não constituam uma camada (social), da mesma maneira que as camadas religiosas. Porém, há casos históricos em que os versados em (algo que genericamente poderíamos identificar como) filosofia, constituem uma camada social, sobretudo, as camadas portadoras do intelectualismo e criadoras das grandes religiões asiáticas (sendo este um ponto importante para o argumento de Weber). Por exemplo, na Índia, os intelectuais provenientes de camadas socialmente nobres, com formação védica, sustentaram a doutrina de salvação do budismo e do jainismo; e as grandes reformas do hinduísmo 
também foram realizadas por intelectuais de camadas socialmente nobres, com formação bramânica, isto é, com formação da camada que ocupava o lugar mais privilegiado da estratificação social indiana. Weber sintetiza o argumento da seguinte maneira:

\begin{abstract}
Apesar de todas as diferenças, são em todos estes casos, camadas intelectuais muito sofisticadas, relativamente, com formação filosófica, correspondentes mais ou menos às escolas filosóficas helênicas ou ao tipo mais aperfeiçoado da formação universitária monacal ou da [formação] secular humanista do fim da Idade Média (WEBER, 2001, p. 268; WEBER, p. 341).
\end{abstract}

$\mathrm{Se}$ as religiosidades do extremo oriente (hinduísmo, budismo, confucionismo e taoísmo) são criações de intelectuais [Intellektuellenschöpfung] e podem ser equiparadas, em parte, a uma filosofia (por isso filosofia oriental), logo, aplicando o mesmo raciocínio para as escolas filosóficas ocidentais, sobretudo as gregas, a filosofia também seria uma criação de intelectuais. Embora não tenha definido ainda o que significa intelectuais, enquanto adjetivação individual, podemos compreender que a filosofia é um produto do intelectualismo, seja ela de qualquer natureza, feita por qualquer camada, grupo ou escola; seja ela helênica, monacal escolástica ou secular humanista.

Antes de prosseguir, gostaria de salientar o sintagma reinterpretação filosófica [phylosophisch Umdeuten] para formular duas questões importantes que resolverei posteriormente: a) o que é reinterpretação filosófica? E, a questão mais central, b) o que é reinterpretação (e consequentemente o que é interpretação)?

A afinidade que Weber aponta entre filósofos/escolas filosóficas e religiosidade asiática (que envolve camadas de sacerdotes, profetas exemplares e burocratas) como portadores do intelectualismo é bastante apropriada para 1) entender como sociedades distintas (isto é, de estruturas sociais distintas) têm, à sua maneira, o elemento comum do intelectualismo; 2) qual pode ser o primeiro limite negativo do condicionamento da estrutura social sobre o intelectualismo; 3 ) considerar a relação que o intelectualismo tem com os indivíduos, para assim chegar a um elemento comum a todos os portadores do intelectualismo. A consideração destas três propostas acima parece possibilitar, enfim, a resposta da principal questão: o que é, então, o intelectualismo?

\title{
3 - OS CONDICIONANTES SOCIAIS DO DESENVOLVIMENTO DO INTELECTUALISMO EM DIFERENTES CONTEXTOS
}


Procuremos elucidar como sociedades distintas têm, a sua maneira, o intelectualismo. Todas as diferentes sociedades, historicamente consideradas, possuem elementos básicos de estratificação social, do ponto de vista econômico. Por um lado, temos a separação entre campo e cidade. Por outro, temos a estratificação em camadas sociais que estão dispostas entre dois tipos-ideais: as negativamente privilegiadas e as privilegiadas (ou mesmo, positivamente privilegiadas).

Uma das conclusões dos estudos de Max Weber sobre religião e sobre a Antiguidade é que as camadas camponesas foram, no transcurso histórico, negativamente privilegiadas socialmente. Somado a isso, o produto do trabalho do homem do campo é tão dependente das condições climáticas que o rodeiam, que ele se torna um refém da imprevisibilidade do clima e da natureza. Afirma Weber que, em regra: "[a camada camponesa] permanece fixada na magia meteorológica e na magia animista ou no ritualismo, sobre o fundamento de uma religiosidade ética, porém, rigorosamente formalista do 'do ut des' em relação ao Deus ou o sacerdote" (WEBER, 2001, p. 222; WEBER, 2009, p. 321). Essa irracionalidade, advinda de sua condição social e existencial no mundo, está refletida na necessidade que as camadas camponesas têm de crenças mágico-soteriológicas, isto é, pelo lado mágico, tentam dominar uma natureza que se impõe de maneira arbitrária e, pelo lado soteriológico, estão à espera de alguém, de uma pessoa extraordinária (carismática), que venha salválas de sua condição de privação material. Por essas condições, os camponeses possuem uma necessidade exterior (econômica) que é uma necessidade pragmática. Em contraposição ao campo, as cidades foram as impulsionadoras e, também, garantidoras do desenvolvimento do racionalismo moderno, de acordo com a argumentação de Weber. Além da cidade ser um local privilegiado para a burocracia, para o direito e, consequentemente, para a escrita, ela é originadora de camadas intermediárias, sobretudo a burguesia. A burguesia manteria uma posição indiferente frente às problemáticas metafísicas, sendo muito mais importante, para ela, uma orientação pragmática em relação ao mundo, marcada pela calculabilidade: "suas condições de existência econômicas têm um caráter muito mais racional, isto é, acessível à calculabilidade e à influência racional, visando a um fim" (WEBER, 2001, p. 241; WEBER, 2009, p. 329).

Já as camadas nobres têm como principal orientação social a legitimação de sua posição privilegiada. Seriam essas camadas que teriam maior liberdade para formulações não necessariamente pragmáticas. No entanto, para legitimar sua posição, são necessárias, em algum grau, adaptações de cunho pragmático. Assim, no caso de uma religião (considerada como produto do intelectualismo), para obter a legitimação perante as 
massas, as criações intelectuais necessitam realizar o esforço de adaptação às necessidades destas, que têm, em seu universo, fortes necessidades pragmáticas (mais precisamente, materiais), sendo a "necessidade interior", senão algo totalmente desconhecido, decerto algo secundário. Com isso, a adaptação, ou melhor, a acomodação das formulações doutrinárias é necessária para a própria sobrevivência da religião que pretende ser universal (e da manutenção da posição social dos portadores desta religião), ocorrendo sempre em sentido mágico-soteriológico e originando produtos diferentes - como veremos no próximo tópico.

As religiões que são criações intelectuais exemplificam melhor esse processo de acomodação, por incorporarem e sistematizarem, em sua doutrina, diversos elementos mágicos e soteriológicos. Desta forma, esses elementos persistiriam no interior de criações do intelectualismo, ainda que o próprio intelectualismo os repugne. Contudo, o processo de adaptação/acomodação não acontece com a mesma intensidade em regiões onde existiam cidades e, por isso, camadas intermediárias. De acordo com os exemplos de Weber, isso ocorreu nos arredores do mundo Mediterrâneo. Como as diferentes sociedades desenvolvem o intelectualismo à sua maneira, ele está relacionado, primeiramente, às relações que os homens têm com o mundo físico e, também, com o modo que o homem habita este mundo, daí a distinção entre campo e cidade. A segunda condição está relacionada à organização interna das sociedades, que são formadas pela distinção entre camadas positivamente privilegiadas e camadas negativamente privilegiadas. A complexificação dessa segunda condição, isto é, da diferenciação social e das suas relações internas, relacionada à primeira condição (diferença entre campo e cidade), constitui uma condição geral das possibilidades do desenvolvimento dos produtos do intelectualismo. Elas são condições gerais da existencial real dos próprios indivíduos que constroem o mundo social. Desta maneira, o intelectualismo é desenvolvido e modulado pela sociedade onde ele se encontra, pois ele é um produto das ações dos homens e suas condições antropológicas/existenciais. Quando tentar definir a relação entre intelectualismo e indivíduo (o terceiro ponto), creio ser possível descrever que condição seria essa.

Vejamos os limites que as camadas sociais exercem sobre o intelectualismo. As camadas camponesas parecem não contribuir positivamente com construções intelectuais. Sua relação com tais construções parece ser negativa, o que é exprimido na acomodação das construções do intelectualismo às suas necessidades. As camadas intermediárias, por sua vez, expressam alguma ambiguidade em relação às construções intelectuais, tanto por sua indiferença e ceticismo, como pela orientação pragmática em relação ao mundo 
econômico. Além disso, vinculado à burguesia e ao fenômeno da cidade, há, em geral, um outro produto do intelectualismo, o Direito. Por fim, as camadas mais privilegiadas, a aristocracia e nobreza de todo tipo, foram aquelas que mais apresentaram contribuições positivas em relação às construções intelectuais. Este ponto parece estar muito próximo ao argumento de $A$ genealogia da moral de Nietzsche: a construção cultural realizada estritamente pelas camadas sociais positivamente privilegiadas - estando a linguagem também aí incluída como expressão do julgamento dessas camadas. Entretanto, Weber refuta a continuação da tese de Nietzsche, que é a afirmação da religião enquanto produto do ressentimento. Vejamos em que medida isso nos ajuda a circunscrever o intelectualismo.

Para refutar a tese de Nietzsche, Weber precisa demonstrar como as teodiceias engendradas pelo sentimento de necessidade de salvação da miséria das camadas negativamente privilegiadas são, na verdade, produto das camadas nobres (positivamente privilegiadas). Nietzsche exacerba o erro ao afirmar que o budismo também seria produto do ressentimento. Em relação a isso, Weber afirma:

Em nenhum outro lugar, os limites da importância do 'ressentimento' e a problemática da aplicação demasiadamente universal do esquema da 'repressão' mostram-se mais claramente do que no erro de Nietzsche ao aplicar seu esquema, também, ao exemplo totalmente inadequado do budismo (WEBER, 2001, p. 264; WEBER, 2009, p. 340).

Como já visto, o budismo é considerado por Weber como uma criação de intelectuais, ou melhor, o budismo é uma criação do intelectualismo levado às últimas consequências. Este seria apenas um exemplo que expressa a possibilidade de outra fonte para a religiosidade.

O intelectualismo, puro enquanto tal, especialmente as necessidades metafísicas do espírito, que medita sobre questões éticas e religiosas, não é impelido por necessidades materiais, mas, sim, pela própria necessidade interna de que se pode apreender o mundo enquanto um cosmos pleno-desentido e nele tomar sua posição (WEBER, 2001, p. 265; WEBER, 2009, p. 341).

O pragmatismo do pensamento e da ação, manifestado na necessidade material dos negativamente privilegiados e no racionalismo prático burguês, diminui as possibilidades de questionamento sobre o sentido do mundo e da existência por parte dos indivíduos. Parece ser este o primeiro fator impulsionador do intelectualismo: a necessidade (metafísica) de sentido do mundo. O intelectual proveniente de camadas inferiores na 
estratificação social está, por toda parte, "ligado ao intelectualismo dos privilegiados por formas intermediárias, diferindo deste pela tendência do seu sentido" (WEBER, 2001, p. 274). Seus portadores são aqueles que se encontram "muitas vezes à beira da existência mínima e dotados de uma educação considerada subalterna” (WEBER, 2001, p. 274). Estão contidos nesse intelectualismo os mais diversos tipos sociais, podendo ser os professores elementares, os cantores, os rapsodos, os judeus piedosos, a inteligência camponesa, os puritanos ingleses do século XVII. Como fez com o "intelectualismo das camadas privilegiadas", Weber também utilizou uma série de nomenclaturas diferentes para este último tipo de intelectualismo, como por exemplo, "intelectualismo proletaróide".

Esses tipos de intelectuais podem se apresentar de maneira mais autônoma por estarem desvinculados de certas convenções sociais, em contraste com os "intelectuais das camadas privilegiadas". Vínculos mais frouxos com convenções sociais aumentariam as chances de uma tomada de posição original em relação ao sentido do cosmos. Na verdade, poder-se-ia pensar que o intelectualismo das camadas positivamente privilegiadas, por sua posição social e pela possibilidade de uma dedicação exclusiva ao exercício intelectual, gozasse de maiores chances de inovar na atribuição de sentido ao mundo, mas o que ocorre é o contrário. Como suas concepções estão fortemente atreladas às convenções sociais, à tradição, elas são levadas mais à manutenção do status quo de sua própria concepção do mundo do que à inovação doutrinal e/ou à mudança social. É claro que seria mais adequado verificar com mais cuidado as possibilidades e a natureza deste status quo, pois certamente elas variam empiricamente.

\section{4 - INTELECTUALISMO NAS RELIGIÕES UNIVERSAIS}

O processo descrito acima se torna ainda evidente nas religiões universais (que são tipicamente criações de intelectuais) quando faltam camadas intelectuais alternativas, que forneçam interpretações também alternativas acerca do conteúdo comum que é alvo das reflexões da camada intelectual dominante. Por exemplo, não há traços significativos de intelectualismo autônomo na China, e foram pouco relevantes para as religiões da Índia. A própria despreocupação com a emancipação face à magia está ligada à não existência de camadas intelectuais intermediárias relevantes, provenientes das camadas inferiores nessas sociedades. Isso leva essas religiosidades, que são criações típicas de intelectuais, à acomodação de suas concepções às necessidades das massas, como já mencionado. As massas, por exemplo, no caso da China e da Índia, são vastas, amplas e 
fundamentalmente camponesas. Assim, por mais que o tipo de religiosidade dominante desvalorize a magia, ele deve se adaptar à magia para sua própria sobrevivência. Não é à toa que em sua exemplificação, Weber inicia com os casos da China e depois da Índia, em uma contagem das diferentes camadas intelectuais que podem exercer influência na religiosidade dominante: na China, essa camada parece ter sido única, a dos mandarins; já na Índia, além da aristocracia (a casta dos xátrias, que possuíam formação védica), havia a casta dos brâmanes. Se migrarmos cada vez mais para o Oriente, o próximo caso das grandes religiões deveria ser o judaísmo.

Em todos os diferentes casos de camadas portadoras do intelectualismo, os indivíduos portadores do intelectualismo (de maneira abreviada, os intelectuais) são o elemento comum e basilar destas. Este tipo de indivíduo apresentaria uma demanda "de sentido para o mundo" vivenciada como uma necessidade psicológica-existencial visceral - o problema do sentido abisma-o, esmaga-o, motiva-o. O grande problema que o envolve e que leva à produção de uma ontologia, de uma metafísica, de uma ética, de uma Weltanschauung (de uma religião e de uma teodiceia) é um fato da vida e deste mundo: a questão da finitude. O intelectual, assim como o caracteriza Weber, não é indiferente à finitude:

A salvação que o intelectual busca é uma salvação de "necessidade interior" e, por isso, por um lado, estranho à vida, porém, por outro, de caráter mais profundo e sistemático do que a salvação da necessidade exterior própria das camadas não privilegiadas. O intelectual busca por caminhos, cuja casuística vai ao infinito, conceder a sua conduta de vida um "sentido" contínuo, assim, uma "unidade" consigo mesmo, com os homens e com o cosmos. A concepção do "mundo", para ele, consuma-se em um problema de "sentido" (WEBER, 2001, p. 273- nossa tradução).

O intelectual teria uma necessidade metafísica de atribuição de sentido a sua vida e ao cosmos. O termo "camadas 'não privilegiadas' " alude aos níveis mais baixos da estratificação social. Praticamente em todas as sociedades que utilizamos como exemplo, as camadas negativamente privilegiadas são muito maiores do que as camadas positivamente privilegiadas. Por isso, a rigor, o intelectualismo é e foi, durante todo esse tempo, um fenômeno de minorias. Isso permite que, como sugere a passagem acima, o intelectual tenha uma espécie de rejeição ou indiferença face ao pragmatismo da vida cotidiana, sendo essa posição, talvez, uma forma até menos digna de vida:

Daí resulta uma forte desclassificação do natural, do corporal, do sensível (...). Algum papel cabe nisto, por vezes, também, ao exigente refinamento e, ao 
mesmo tempo, à repressão da sexualidade normal em favor das reações substitutivas, devido à conduta de vida do indivíduo que nada mais pretende ser que um intelectual, como parece demonstrar, de forma palpável, certos fenômenos, particularmente dos mistérios gnósticos - sublimados substitutivos masturbatórios das orgias dos camponeses (WEBER, 2001, p. 271-2- nossa tradução).

Veem-se os meios tomados pelo intelectual, a fim de atribuir sentido total para o cosmos e, principalmente, para sua própria vida; faz dela uma unidade coerente e a leva a uma sistematicidade de conduta global, que reprime a sexualidade. $\mathrm{Na}$ verdade, a repressão das sensações pode ser explicada pelos próprios termos weberianos. Contudo, a explicação não deixa de ser simples. Uma vez que, segundo Weber, o amor (leia-se aqui, sobretudo, a sexualidade) é a força mais irracional da vida, logo, o intelectual que visa à unidade, à sistematicidade de sua conduta global de vida repreenderia a sexualidade; seria como um desenvolvimento levado às últimas consequências da valorização de um sistema ideal de vida que possui um sentido metafísico, por um lado, e, por outro, da desvalorização de tudo aquilo que é pragmático, das necessidades mais imediatistas da existência e, especialmente, dos sentimentos e sensações. Além disso, a desvalorização das questões práticas da vida, quando a cultura intelectual é tomada como valor último pelo indivíduo intelectual, tende a levá-lo para fora da vida política.

Por fim, ainda há a figura histórica, individual e carismática do profeta, que é de grande relevância para a argumentação de Weber sobre o desenvolvimento das religiões. Ela está vinculada diretamente aos problemas gerados pela necessidade interna, problemas estes relacionados à finitude e ao sentido do mundo. Por isso, a profecia sempre se refere a "um aspecto unitário da vida, conseguido por meio de uma tomada de posição de uma unidade com-sentido [einheitliche sinnhafte Stellungnahme]" (WEBER, 2001, p. 193; WEBER, 2009, p. 310), posição esta tomada pelo profeta: "A vida e o Mundo, os acontecimentos sociais, assim como os cósmicos, têm para o profeta certa unidade sistemática de "sentido", e o comportamento dos homens, para que lhes traga o paraíso, deve orientar-se por isso e, por meio desta relação, assumir uma unidade plena-de-sentido [sinnvol]" (WEBER, 2001, p .193; WEBER, 2009, p. 310).

O primeiro passo, portanto, é a atribuição de sentido total (de cunho metafísico) para o mundo que serve de núcleo-duro, enquanto outros elementos gravitam ao seu redor e, eventualmente, são sistematizados. A última questão metafísica é: "Se o mundo como um todo e a vida, em especial, têm um sentido, então: qual pode ser este sentido? E como o mundo deve se apresentar para lhe corresponder?" (WEBER, 2001, p. 194; WEBER, 2009, 
p. 310). Como consequência das respostas a tais questionamentos, a questão do "sentido" implica em certo desenvolvimento ético, isto é, na orientação da ação dos homens em suas vidas cotidianas. É gerada, neste caso, uma Lebensführung, uma conduta de vida global. Ao conceber sua própria concepção sobre o mundo, ao responder à pergunta do sentido (ou do ponto de vista subjetivo do profeta, quando o sentido do mundo é revelado ao profeta, isto é a anunciação de uma verdade religiosa que lhe revela os caminhos para a salvação), o sentido do cosmos tem como referência (significado) central a salvação. Concebida a finalidade do mundo e, assim, seu sentido, os caminhos para atender tal finalidade farão com que as proposições do profeta tornem-se sempre "uma busca por sistematização de todas as expressões da vida e também do comportamento prático rumo a uma conduta de vida (...)" (WEBER, 2001, p. 193; WEBER, 2009, p. 310).

A concepção do mundo e seu sentido orientam a ação (a semântica orienta a pragmática) e toda experiência dos indivíduos. A unidade de sentido para a vida implica uma condução única sobre esse sentido. Nos argumentos trabalhados até aqui, "sentido" mantém a acepção da própria origem da palavra: a "ideia" de direção, um caminho. $\mathrm{O}$ intelectualismo é, até então, o elemento que reflete este sentido. Mas a problemática religiosa dos profetas e sacerdotes é o colo materno do qual se desprendem a filosofia não sacerdotal, ali onde ela se desenvolveu, para depois ter de enfrentar, como um componente muito importante do desenvolvimento religioso, essa problemática (...). A profecia não é a única instância que tem de lidar com este problema. Também toda sabedoria não sacerdotal, a intelectualista e a vulgar, ocupam-se dele de alguma maneira (WEBER, 2001, p. 193). Com isso, o problema de "sentido" do profeta é, por toda parte, um problema de sentido de filósofos, cientistas e éticos. É um problema referente ao homem. Weber oferece um resumo a isto, em uma afirmação presente na Introdução [Einleitung]:

Uma proposição [Stellungnahme] está presa atrás de algo que, no mundo real, seria percebido como especificamente "sem sentido" e, assim, a demanda de que o arranjo do mundo [Weltgefüge], em sua totalidade seja, de algum modo, um 'Cosmos' pleno-de-sentido ou, que possa ser um ou deva ser um. Mas isso requer o produto do núcleo do próprio racionalismo religioso que tenha sido inteiramente realizado pelas camadas intelectuais. Os caminhos e os resultados dessa necessidade metafísica e também o grau de sua efetividade foram aí muito distintos (WEBER, 1989, p. 102 - tradução nossa).

Portanto, o mundo, a natureza, o âmbito da coisa-em-si são sem sentido. Tudo o que é da ordem do sentido é produto da relação do homem com o mundo que ele habita, a partir de uma demanda necessária de seu "ser" (de sua estrutura cognitiva) de atribuir sentido 
para aquilo que não possui sentido. A construção do cosmo com sentido é o núcleo da ação do intelectualismo, manifestado, sobretudo na religião, por sua tentativa de fornecer um sentido total para o cosmos. O intelectualismo, portanto, é um efeito da necessidade antropológica/ontológica (ou da própria estrutura cognitiva do homem) de atribuição de sentido ao mundo em geral, gerando um pensamento metafísico e ético. Embora não apareça explicitamente, o sentido metafísico e ético está submetido às exigências lógicas do pensamento, sobretudo, à necessidade de coerência e consistência. Como consequência, há a constante exigência do pensamento de sistematicidade de seus conteúdos. Toda operação do pensamento humano, que busque a atribuição de sentido ao mundo, e a exigência da sistematicidade de seus conteúdos, está relacionada ao intelectualismo: a religião, a especulação filosófica, a metafísica, o desenvolvimento do pensamento ético e teórico em geral. A magia também estaria inserida nesta definição, por ser um produto de elaboração dos dados sensíveis do mundo pelo pensamento que exige algum grau de sistematicidade e coerência. Porém, a todo instante, há uma forte tensão entre intelectualismo e magia. Weber indica, em vários momentos, a rejeição que o primeiro tem sobre o último. Essa rejeição em seu aspecto epistemológico está relacionada ao grau que o pensamento crítico é operado na magia. Para tanto, o intelectualismo, ao se desenvolver, leva ao desencantamento do mundo.

\section{5- SOBRE INTELECTUALISMO E LINGUAGEM: UMA SÍNTESE}

Outra característica importante do intelectualismo é a objetivação do pensamento e do conhecimento, seja qual for sua origem. Das formas possíveis de objetivação, a mais forte parece ter sido a linguagem escrita. A capacidade de leitura e escrita são condições primárias para a definição primeira do que viria a ser um intelectual. Na medida em que algum indivíduo aprende como utilizar a escrita, existiria um sistema educacional que vincula automaticamente esse indivíduo a algum sistema de concepções. Embora a condição basilar de leitura e escrita textual defina o que torna alguém intelectual ou não, podemos formulá-la em sentido mais genérico e ainda provisório. É a capacidade de interpretação dos conteúdos textualmente formalizados de concepções previamente existentes, formadas pelo pensamento, que define um intelectual no sentido do processo de intelectualização.

O intelectualismo tem sua existência de forma pura apenas no plano lógico. Ele necessariamente deve estar incorporado em pessoas concretas. Para tanto, camadas 
sociais, grupos e indivíduos sempre serão os portadores do intelectualismo. O grau de dependência de um intelectual à sua respectiva camada intelectual é bastante variável, podendo apenas ser dado pelo mundo empírico. Há casos, por exemplo, em que o grau de dependência é bastante fraco, como no caso dos fundadores de escolas, de doutrinas e até mesmo de novas religiosidades (como os profetas). O grau de dependência envolve alguns fatores como a margem de liberdade de ação do intelectual (a respeito de proposições intelectuais) e a margem de influência que a tradição em que o intelectual está inserido exerce sobre ele. Entendemos, portanto (assim como, certamente, Weber entende), que sempre há um vínculo (maior ou menor) com um conjunto de conhecimentos já estabelecidos (sedimentados) que compõe o contexto semântico (um background) de qualquer nova concepção (que mais à frente será entendida por nova interpretação) cognitivamente construída e objetivada (eventualmente, até mesmo, objetificada). Provisoriamente, o contexto semântico sedimentado serve de base para qualquer tradição. O ponto central é que os contextos semânticos são utilizados, reatualizados (pragmaticamente) por certo conjunto de pessoas, ou grupos, pois o contexto viabilizaria a expressividade de certos estados mentais que, a princípio, estariam isolados na subjetividade de um indivíduo. O contexto semântico viabiliza, assim, a própria comunicação. Portanto, para que qualquer nova interpretação seja realizada e então objetivada, há a necessidade de vínculo com algum contexto semântico (como visto, um contexto de significados e sentidos) e, consequentemente, o vínculo com algum grupo.

\section{6- CONCLUSÃO}

Pelo exame do intelectualismo, chegamos a três caminhos diferentes que endereçam parte do complexo de problemas relativos ao conhecimento: a.) os problemas epistemológicos (de uma Erkenntnistheorie) mais centrais surgem quando tentamos definir o que é a magia, qual a sua relação com o mundo e qual a sua relação com o intelectualismo; b.) a forma da existência real do conhecimento e sua mudança estão na relação entre objetivação - interpretação e; c.) o conteúdo atual do conhecimento, sua mudança e a relação pragmática que este tem com as pessoas dependem do contexto semântico (NERI, 2014).

O primeiro ponto nos leva a refletir sobre qual é o papel do processo de intelectualização no processo de transformação do âmbito de atuação da magia em um 
âmbito cada vez mais irracional. O conflito que o intelectualismo tem com a magia não é apenas a oposição à sua orientação pragmática de ação; está localizado também na inconsistência objetiva com que este tipo de pensamento pretende ao compreender o mundo. O tipo de procedimento do pensamento mágico está totalmente construído sobre o pensamento analógico. Este tipo de pensamento não deixa de existir quando a magia vai sendo afastada, ele subsiste até mesmo como ferramenta explicativa no pensamento científico. Porém ele sempre apresenta problemas por aproximar dois eventos que não estão dados a aproximações em um primeiro momento. O procedimento causal, desta maneira, não consegue residir sobre a conexão de fatos relativamente conhecidos, mas sobre a crença da conexão destes fatos. Mas no pensamento mágico, a analogia é levada ao extremo da significação: o mundo pode apresentar seu próprio sentido, independentemente de qualquer atribuição de sentido por uma mente humana, havendo a existência de espíritos em tudo, uma espécie de projeção antrópica no mundo inanimado. O próprio processo de abstração, que gerou a crença em espíritos, segundo o argumento de Weber, se continuar em curso, levará às novas abstrações, construindo, assim, conceitos mais gerais sobre o suprassensível - como veremos logo a seguir. Com isso, o processo de afastamento da magia seria uma das consequências do processo de desenvolvimento do conhecimento, que tem por base a atribuição de sentido geral à totalidade do mundo e do cosmos e a ordenação e sistematização de todos os conteúdos produzidos pela cognição humana, tendo este idealmente sentido último como referência. Assim, em uma passagem muito importante que trata do desencantamento do mundo, Weber argumenta que:

Quanto mais o intelectualismo sufoca a crença na magia e, assim, os fenômenos do mundo se desencantam, perdendo seu sentido mágico, somente "são" e "acontecem", mas nada "significam", tanto mais cresce a urgência com que se exige do mundo e da "conduta de vida", como um todo que tenham uma significação e estejam ordenados segundo um "sentido" (WEBER, 2001, p. 273).

O estabelecimento de um cânone e, principalmente, a composição de uma dogmática como um produto intelectualista anti-intelectualista. Isto é, um produto que tente impedir o próprio desenvolvimento do intelectualismo, sufocando interpretações futuras. São estes os elementos que, de alguma maneira, dão o solo ao fenômeno da fé. A fé, em parte, sempre consiste na aceitação de certa dogmática; para tanto, a fé, a crença em certas concepções, sempre garante, em parte, o objetivo do status quo das arquitetônicas sagradas. 
O segundo ponto diz respeito ao processo de objetivação - interpretação. A formação de um conjunto de significados (em um primeiro momento causado pelo acúmulo gradual de produtos da objetivação) passa por um ato de sistematização que é característico da própria cognição humana. Embora a abstração ainda exista, o processo de sistematização requer o ordenamento e atribuição de sentido de ideias abstratas. Esse tipo de ação voltada à geração de conhecimento (praticada, sobretudo, na ciência) é o que chamamos de interpretação positiva. A interpretação positiva ordena uma série de elementos que são intencionalmente escolhidos e consequentemente subordinados a significados. A ideia que subjaz ao adjetivo "positivo" é relativa ao processo que estamos enfatizando aqui: se interpretação é o ato cognitivo que toma alguns elementos e os organiza sob esquemas interpretativos, a interpretação positiva adiciona a essa cadeia de ações a objetificação de uma interpretação particular. Interpretação positiva é, portanto, o processo que envolve atos de compreensão, revisão, sistematização e finalmente objetificação. Nesse sentido, interpretação positiva diz respeito a dois fatores: um interno e outro externo. O primeiro diz respeito à coerência e possibilidade de desenvolver conceitos limitados dada a objetividade independente de um indivíduo. E o segundo diz respeito à adequação pragmática de interesses pragmáticos em geral (NERI, 2014).

E por fim, o terceiro ponto diz respeito ao contexto semântico. $O$ ato de atribuir significado ao mundo é o ato de tornar inteligíveis partes do mundo para um certo número de pessoas, gerando assim um mundo de significados (isto é, um contexto semântico) que guia a ação dos indivíduos. A formação de um contexto semântico se desenvolve ao longo do tempo e é fruto de um conjunto de ações de atribuição de sentido e consequente objetificação, que torna possível o acesso do mesmo por diversos indivíduos. Os significados estariam dispostos conforme uma constelação semântica orbitando em torno da gravidade do sentido último estabelecido naquela constelação. E este sentido último é sempre a expressão da condição universal do homem: sua finitude. Como vimos, portanto, o principal problema epistemológico da magia é justamente a confusão entre a coisa representada e a coisa em si, fundindo signo e sentido/significado. Assim, a magia não permite interpretações positivas, porque se baseia na fórmula mágica. A fórmula mágica procura sujeitar o sagrado a seu domínio, portanto, se coloca como invariável. Por mais que haja desenvolvimentos a partir do conhecimento mágico, do ponto de vista da magia esse desenvolvimento não é possível, pois uma fórmula mágica reinterpretada é uma nova fórmula mágica. Portanto, uma nova interpretação no campo da magia sempre representa um novo começo. 


\section{REFERÊNCIAS}

DEININGER, J. A teoria econômica dos Estados Antigos. Tempo Social: dossiê Max Weber. Julho, 2012. pp. 61-84.

PIERUCCI, Antônio Flávio. O desencantamento do mundo: todos os passos do conceito em Max Weber. São Paulo: Editora 34, 2003.

NERI, Hugo. O Processo de Intelectualização: fundamentos para uma explicação sociológica do conhecimento. Dissertação de Mestrado. Faculdade de Filosofia, Letras e Ciências Humanas, Universidade de São Paulo. São Paulo, 2014.

NIETZSCHE, Friedrich. Genealogia da Moral. São Paulo: Cia das Letras, 2009.

WEBER, Max. Economia e Sociedade v.I. Brasília: UNB, 2009.

WEBER, Max. Hinduismus und Buddhismus 1916-1920. In.: SCHIMIDT, Glintzer \& GOLZIO, Karl-Heinz. Max Weber-Gesamtausgabe (MWG): I/20 Die Wirtschaftsethik der Weltreligionen. Tübingen: Mohr Siebeck, 1996.

. Die Wirtschaft und die gesellschaftlichen Ordnungen und Mächte. Nachlaß. Religiöse Gemeinschaften. In.: KIPPENBERG, Hans; SCHILM, Petra Schilm \& NIEMEIER, Jutta Niemeier. In.: Max Weber-Gesamtausgabe I/22-2 Wirtschaft und Gesellschaft. Tübingen: Mohr Siebeck, 2001.

.Einleitung fur Konfuzianismus und Taoismus. Schriften 1915-1920. In.: SCHIMDT-GLINTZER, Helwig \& KOLONKO, Petra. Max Weber-Gesamtausgabe (MWG): I/19 Die Wirtschaftsethik der Weltreligionen. Tübingen: Mohr Siebeck, 1989.

VERLAG. Historisches Wörterbuch der Philosophie v.4. Basel: Schwabe \& CO Verlag, 1976.

\section{NOTAS}

\section{TÍTULO DA OBRA}

Intelectualismo em Max Weber: O processo de intelectualização como um caminho para compreensão do desenvolvimento histórico do conhecimento.

Bacharel e licenciada em Ciências Sociais pela Universidade de São Paulo; mestre em Sociologia pela Universidade de São Paulo e doutora em Sociologia pela Universidade de São Paulo. Universidade de São Paulo (USP), São Paulo, Brasil.

veridiana.cordeiro@usp.br

https://orcid.org/0000-0001-9666-4386 (D) 


\section{Hugo NERI}

Graduado em Ciências Sociais pela Universidade de São Paulo; mestre em Sociologia pela Universidade de São Paulo e doutor em Filosofia pela Universidade de São Paulo. Universidade de São Paulo (USP), São Paulo, Brasil.

hugo.munhoz@usp.br

https://orcid.org/0000-0001-6065-4661

LICENÇA DE USO - uso exclusivo da revista

Os autores cedem à Em Tese os direitos exclusivos de primeira publicação, com o trabalho simultaneamente licenciado sob a Licença Creative Commons Attribution 4.0 Internacional (CC BY). Estra licença permite que terceiros remixem, adaptem e criem a partir do trabalho publicado, atribuindo o devido crédito de autoria e publicação inicial neste periódico. Os autores têm autorização para assumir contratos adicionais separadamente, para distribuição não exclusiva da versão do trabalho publicada neste periódico (ex.: publicar em repositório institucional, em site pessoal, publicar uma tradução, ou como capítulo de livro), com reconhecimento de autoria e publicação inicial neste periódico.

PUBLISHER - uso exclusivo da revista

Universidade Federal de Santa Catarina. Programa de Pós-Graduação em Sociologia Política. Publicado no Portal de Periódicos UFSC. As ideias expressadas neste artigo são de responsabilidade de seus autores, não representando, necessariamente, a opinião dos editores ou da universidade.

\section{HISTÓRICO}

Recebido em: 30 de junho de 2020

Aprovado em: 14 de dezembro de 2020 